
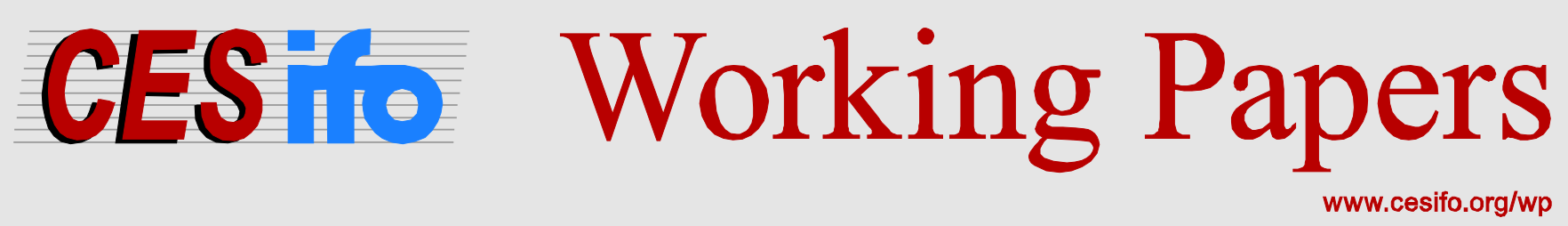

\title{
Modeling UK Natural Gas Prices when Gas Prices Periodically Decouple from the Oil Price
}

\author{
Frank Asche \\ Atle Oglend \\ Petter Osmundsen
}

\author{
CESIFO WORKING PAPER NO. 5232 \\ CATEGORY 10: ENERGY AND ClimATE ECONOMICS \\ FEBRUARY 2015
}

An electronic version of the paper may be downloaded

- from the SSRN website:

- from the RePEc website:

- from the CESifo website:

WwW.SSRN.com

Www.RePEc.org

www.CESifo-group.org/wp

ISSN 2364-1428

\section{CESifo}




\title{
Modeling UK Natural Gas Prices when Gas Prices Periodically Decouple from the Oil Price
}

\begin{abstract}
When natural gas prices are subject to periodic decoupling from oil prices, for instance due to peak-load pricing, conventional linear models of price dynamics such as the Vector Error Correction Model (VECM) can lead to erroneous inferences about cointegration relationships, price adjustments and relative values. We propose the use of regime-switching models to address these issues. Our regime switching model uses price data to infer whether pricing is oildriven (integrated) or gas-specific (decoupled). We find that UK natural gas (ICE) and oil (Brent) are cointegrated for the majority of the sample considered (1997-2014). Gas prices tend to decouple during fall and early winter, when they increase relative to oil consistent with heating demand for natural gas creating gas-specific pricing. Using the model to infer relative values when evidence favors integrated markets, we find that the industry 10-1 rule-of-thumb holds, meaning that the value of one barrel of oil is 10 times the value of one MMbtu of natural gas.
\end{abstract}

JEL-Code: F130, Q270, Q480, Q350, Q410.

Keywords: oil, natural gas, peak load pricing, regime switching, relative value.

Frank Asche

Department of Industrial Economics University of Stavanger / Norway frank.asche@uis.no
Atle Oglend*

Department of Industrial Economics

University of Stavanger / Norway

atle.oglend@uis.no

\author{
Petter Odmundsen \\ Department of Industrial Economics \\ University of Stavanger / Norway \\ petter.osmundsen@uis.no
}

*corresponding author

This paper is based on the previous working paper Asche, Oglend, et al. (2013). We would like to thank a number of specialists in business and the civil service for useful comments and proposals. Financial support from the Norwegian Research Council (Petrosam 2) is appreciated. 


\section{Introduction}

This paper proposes the use of regime-shifting models (Hamilton, 1989; Hamilton and Susmel, 1996) as an empirical approach to model natural gas prices when gas prices are subject to periodic decoupling from oil prices. Periodic decoupling, or gas-specific pricing, is the result of changes in the marginal valuation of natural gas due to changing market conditions. Peak load pricing, for instance, is generally associated with natural gas prices determined by the immediate use demand for electricity generation or in direct heating. Oil is unlikely to play a large role in natural gas pricing under such conditions. When natural gas infrastructure is available and use demand lower, the marginal consumer is more likely to value natural gas relative to oil. Storage injection and delivery on oil-indexed flexible contracts imply a natural gas price informed by oil. Accounting for changes in marginal valuation is an empirical challenge, as the marginal consumer is, in general, not identified. Conventional log-linear models, such as the Vector Error Correction model (VECM), will average estimates over all pricing states. If pricing of natural gas periodically decouples from the oil price, the linear estimator becomes biased. The degree of market integration will tend to be underestimated, and the relative value of natural gas to oil overvalued. Our empirical approach allows us to account for periods of oil-driven or gas specific pricing of natural gas, and thus implicitly differentiate between state changes in marginal valuation. This will allow a more detailed and accurate treatment of natural gas pricing and the relative value of natural gas to oil. Knowledge about relative prices are important for evaluating effects of gas market deregulations, for determining the relevance of oil indexation in gas contracts, for company decisions regarding investments in oil or gas projects, and for investments in energy-asset portfolios.

There are reasons to believe that both gas-specific factors and oil influences the UK natural gas price. During the last decades, demand for gas in Europe has more than doubled (Asche et al., 2008). This is largely due to increased use of natural gas in the power sector. Combined cycle gas turbine technology in gas-fired power plants has increased fuel efficiency and requires lower capital and 
operating costs. Gas-fired power primarily competes against coal and nuclear power, and the increased share of UK natural gas consumption for gas-fired power plants potentially contributes to a weaker link towards oil. However, gas in continental Europe still mostly trades on long-term contracts indexed to fuel prices, including oil. This creates a strong link between continental European gas prices and oil (Asche et al., 2002; Siliverstovs et al., 2005; Asche et al., 2006; Panagiotidis and Rutledge, 2007; Asche, Misund, et al., 2013). Since the UK is connected to the continent by the Interconnector, the oil link is likely to transfer to UK prices.

In markets where gas-to-gas competition is stronger, such as the US, the relationship between oil and natural gas prices is weaker (Villar and Joutz, 2006; Parsons and Ramberg, 2012), and natural gas is priced as more of a unique commodity in and of itself (Serletis and Herbert, 1999; Brown and Yucel, 2008; Bencivenga et al., 2011). In the US, the weak link between oil and natural gas has been reinforced by the shale gas expansion (Kerr, 2010). Excess supply from shale production has led to fully decoupled US gas and oil prices (Erdos, 2012; Oglend et al., 2016). Shale gas has led to a dramatic reduction in US demand for LNG imports. Some LNG shipments, which would initially go to the US, would end up in Europe or Asia. In Japan, LNG is mostly traded on long term contracts indexed to a crude oil price (in $2013,73 \%$ of LNG trades took place under long term contracts (Agerton, 2014)). Some LNG imports to Europe would therefore also reflect oil indexation.

UK gas trade has seen an increase in spot trade since deregulation. Before deregulation, there was a direct link between oil and natural gas prices due to the pricing formulas used in long-term contracts. More spot trade means stronger gas-to-gas competition and more gas-specific pricing. Moreover, there was little or no evidence of peak load pricing before deregulation as local retail monopolies tended to overinvest in capacity. Gas-specific pricing is likely to manifest strongly when natural gas demand is close to availability, and gas infrastructure is close to full capacity utilization, typically during cold winter days when demand for heating is high. Interspersed periods of gas-specific pricing 
suggest that prices move between being decoupled and integrated with oil. A somewhat similar dynamic is observed in electricity markets (Lucia and Schwartz, 2002; Mount et al., 2005; Geman and Roncoroni, 2006; Kanamura and hashi, 2008). In electricity markets, a hockey stick shaped supply curve gives rise to changes in pricing regimes within trading days. When capacity utilization is high in mornings and afternoons, electricity prices might display the characteristic spiking behavior. Electricity and natural gas however differ at a fundamental level. Gas can be stored, allowing intertemporal supply smoothing. We would therefore expect peak-load pricing to be less extreme and more persistent over time. Storage allows buffering of supply and demand shocks, with subsequently less extreme price movements. Related to our work, Brigida (2014) apply a regime switching model to the linear long-run relationship between Henry Hub natural gas and WTI oil prices. He finds evidence of state-dependency in the long-run relationship. Our work differs by focusing on periodic complete decoupling of natural gas from oil prices related to periods of unique gas pricing. We allow the full error-correction model of natural-gas prices to shift between states. The state processes are restricted such that pricing can move in and out of co-integration.

This paper is structured as follows. In the next section, we investigate the consequences of periodic decoupling when modeling natural gas prices. We show that periodic decoupling leads to biased linear estimates of integration and valuation. We proceed by proposing a regime-switching model that can account for these issues. The model is estimated on UK natural gas and Brent oil prices. Finally, we discuss the results from the model and the validity and specification of the model.

\section{Consequences of Periodic Decoupling}

Natural gas in the UK is used for direct heating as well as fuel in electricity generation. On a mild winter with sufficient gas infrastructure, seasonality in demand is unlikely to have large price effects. On the other hand, when demand is high relative to availability, substantial price adjustments are likely, leading to peak load pricing. If immediate gas availability is A and demand D, net gas 
availability is $\mathrm{X}=\mathrm{A}-\mathrm{D}$. As net availability approaches zero, price and volatility increases. This property of commodity prices is well known in the competitive storage literature (Wright and Williams, 1991; Deaton and Laroque, 1992; Pirrong, 2012). During peak load pricing, marginal gas is valued by its marginal revenue productivity in electricity generation or heating. The gas infrastructure tends to be close to full capacity utilization and oil indexation is unlikely to influence gas pricing.
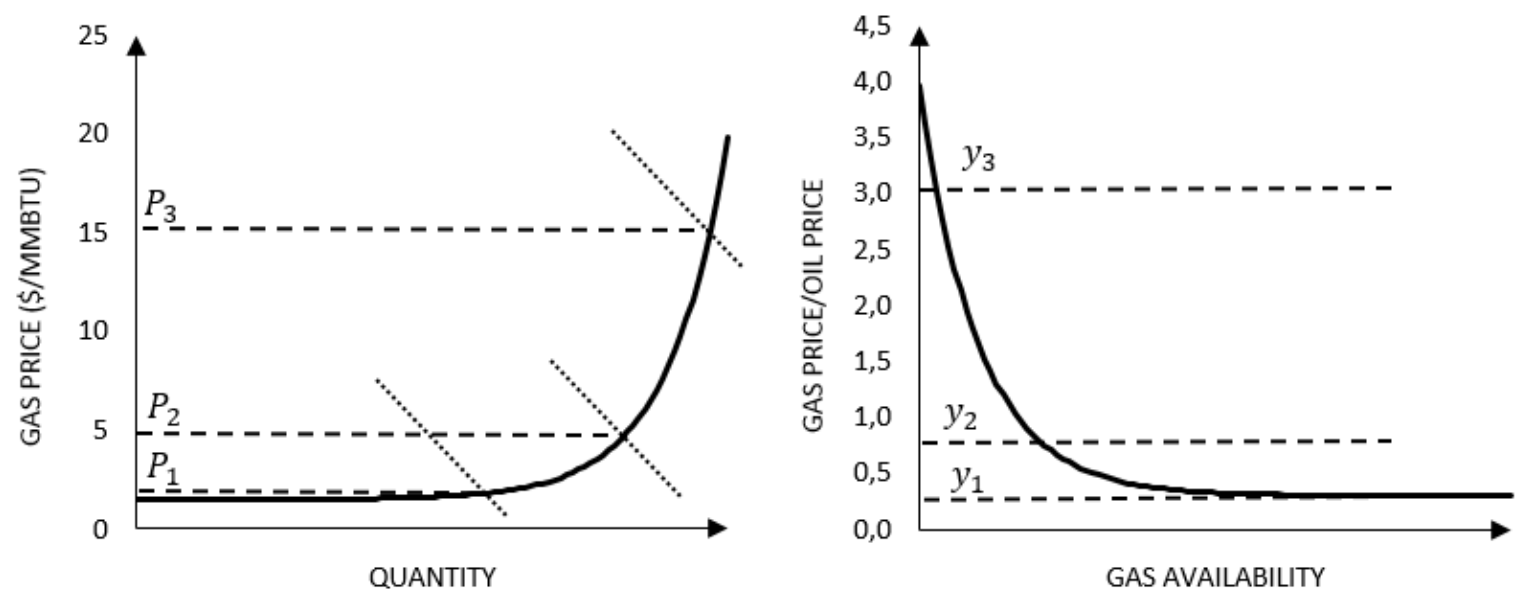

FIGURE 1. Pricing of natural gas and the oil/natural gas relative price.

The left panel of figure 1 illustrates gas prices for a set of demand schedules and a marginal-cost setup. The right panel shows the associated relative price curve as a function of gas availability, here for a given oil price. If the oil price is exogenous, the relative price curve (right panel) does not shift systematically as gas prices change. If oil prices adjust instantaneously and proportionally to gas market conditions, the relative price curve will be a straight line at the equilibrium relative price. Peak load pricing implies a strictly convex supply curve; downward shifts in demand (resulting in prices going from $P_{2}$ to $P_{1}$ ) results in smaller price movements than equivalent increases in demand (going from $P_{2}$ to $P_{3}$ ). If natural gas is only oil driven when net availability is high and gas infrastructure available, the relative value of natural gas to oil will, for a given distribution of net availability, be overestimated when using conventional linear estimators of price relationships. 
To see this, let $z_{t}$ be the relative price of natural gas to oil and $\mu$ the equilibrium relative value. When markets are integrated and the law of one price holds, $E\left(z_{t} \mid\right.$ integration $)=\mu$. During gas-specific pricing, there is no equilibrium relative value in any economic sense, and $E\left(z_{t} \mid\right.$ decouple $) \neq \mu$ (unless by statistical chance the expected relative price when decoupled is $\mu$ ). The OLS estimator of $\beta_{0}$ in the simple linear regression $z_{t}=\beta_{0}+\varepsilon_{t}$ is just the sample mean $\widehat{\beta_{0}}=\frac{1}{T} \sum_{t=1}^{T} z_{t}$. This will not tend to $\mu$ because $E\left(z_{t}\right)=\rho E\left(z_{t} \mid\right.$ integration $)+(1-\rho) E\left(z_{t} \mid\right.$ decouple $) \neq \mu$, where $\rho$ is the unconditional probability of market integration. Only if markets are at all times integrated $(\rho=1)$, would $\widehat{\beta_{0}}$ tend to $\mu$. For a convex relative price curve as in figure 1 the expected relative price is likely to be higher than the equilibrium price when decoupled, $E\left(z_{t} \mid\right.$ decouple $)>\mu$ and $E\left(z_{t}\right)>\mu$ for $\rho \neq 1$. The unconditional sample mean estimator would overvalue natural gas relative to oil.

We perform a simple simulation experiment to evaluate how sensitive a linear error correction model is to periodic decoupling. Let $y_{t}$ and $x_{t}$ be two $(\log )$ prices. We assume $x_{t}$ is exogenous to $y_{t}$ and that $y_{t}$ follows a periodic decoupling process

$$
\begin{gathered}
\Delta x_{t}=\sigma_{1} \epsilon_{x, t} \\
\Delta y_{t}=s_{t}\left(\mu_{1}+\alpha\left(y_{t-1}-\beta x_{t-1}\right)\right)+\left(1-s_{t}\right) \mu_{2}+\epsilon_{y, t}
\end{gathered}
$$

where $\epsilon_{x, t}$ and $\epsilon_{y, t}$ are standard normal variables. The binary variable $s_{t}$ determines if markets are integrated, and it follows the Markov process

$$
\left[\begin{array}{c}
s_{t+1} \\
1-s_{t+1}
\end{array}\right]=\left[\begin{array}{cc}
1-q & 1-q \\
q & q
\end{array}\right]\left[\begin{array}{c}
s_{t} \\
1-s_{t}
\end{array}\right]+v_{t+1}
$$


where $v_{t+1}$ is a Markov difference sequence accounting for the forecast error of the Markov chain. The parameter $q$ is the fraction of periods prices are decoupled. When $q=0$, prices are integrated at all times, when $q=1$, markets are always decoupled.

We set $\beta=1, \mu_{1}=-0.025, \alpha=-0.05$ and $\mu_{2}=0.025$. When $s_{t}=1, x_{t}$ and $y_{t}$ are cointegrated and the law of one price holds with an equilibrium relative value $(y / x)$ of $\exp \left(\frac{-\mu_{1}}{\alpha}+\frac{\left(\sigma_{1}\right)^{2}}{2}\right)$. When $s_{t}=0, y_{t}$ decouples from $x_{t}$ and follows a random walk with positive drift $\mu_{2}$. We vary $q$ from zero to 0.85 in intervals of 0.05 and simulate 10000 price series of length 1000 for each $q$. For each simulated price series, we estimate the linear error correction model $\Delta y_{t}=\mu+\alpha\left(y_{t-1}-\beta x_{t-1}\right)+$ $\varepsilon_{t}$. We proceed to investigate the mean and standard deviation of the OLS estimates for $\hat{\alpha}$ and $\hat{\beta}$, the sample mean of the relative value, and the skewness and kurtosis in the empirical distribution of $\varepsilon_{t}$. 


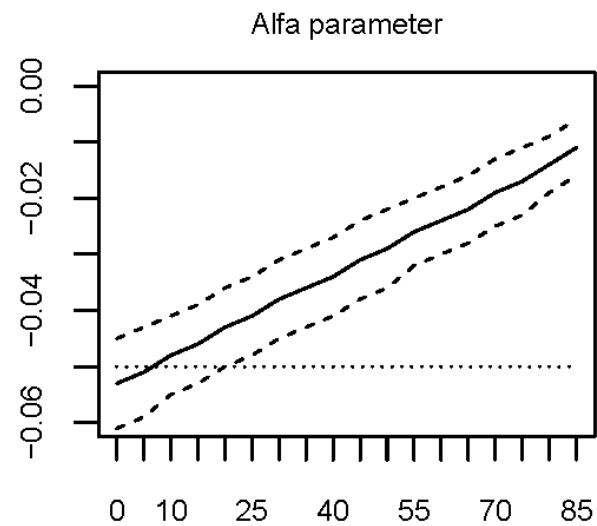

$\%$ time decoupled

Relative value

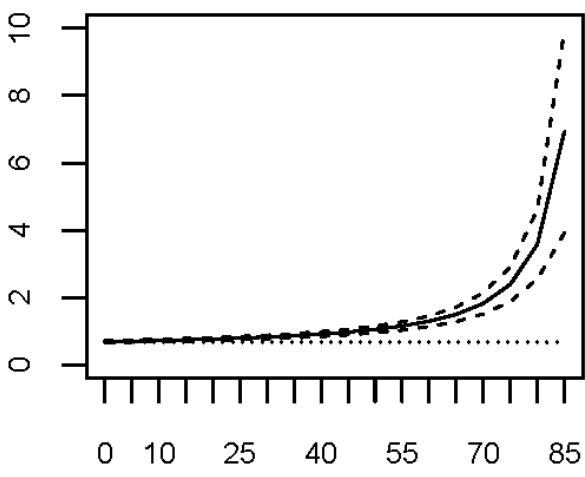

$\%$ time decoupled
Beta parameter

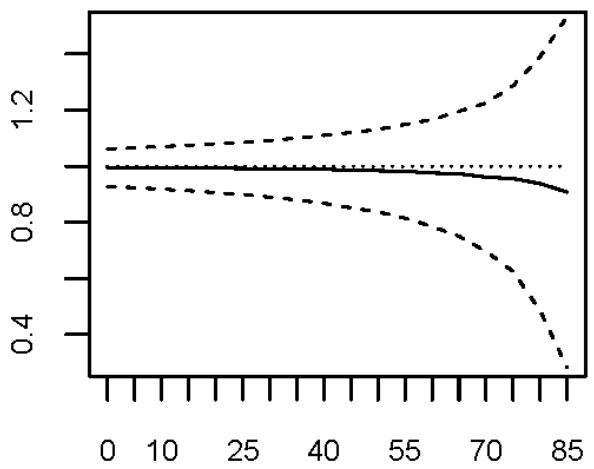

$\%$ time decoupled

Skewness (green), Kurtosis(red)

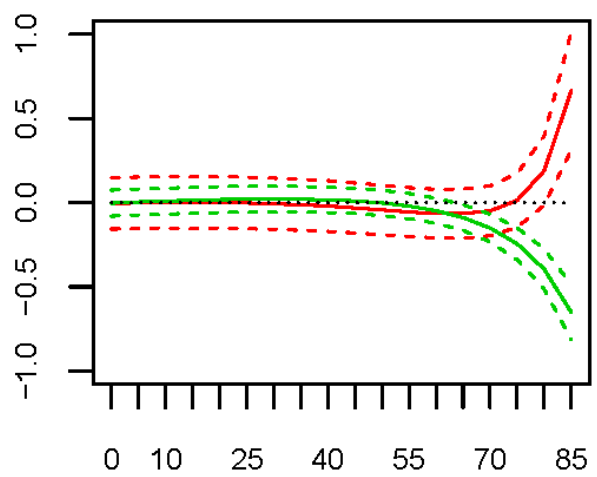

$\%$ time decoupled

Note: Solid line is the mean OLS estimate, dotted lines are mean +/- the standard error of the estimates. The small dotted line is the true value under $100 \%$ integration.

FIGURE 2. Estimation bias of linear error correction models

The alpha parameter (top left panel in figure 2) measures the adjustment in $y_{t}$ to deviations from the equilibrium relationship. As decoupling becomes more prevalent, the estimate becomes smaller in magnitude. This is because the linear estimator averages over all states, even when no adjustment in $y_{t}$ occurs. The beta parameter describes the normalized (by $y_{t}$ ) cointegration relationship between $y_{t}$ and $x_{t}$. The linear estimate displays a downward bias relative to the full integration case when decoupling increases. The standard error of the estimator also increases substantially as decoupling becomes more prevalent. This means that the estimated long-run equilibrium relationship appear weaker than what we would infer if we could account for when markets are integrated. Consequently, the law of one price will be over-rejected in the linear model. Looking at the sample 
mean of relative values, this has a substantial positive bias as decoupling increases. This is because of the positive drift in gas prices under decoupling. If a meaningful relative value derives from an economic relationship between the commodities, it should be inferred only in periods where integration is present, and should not include periods of decoupling. As decoupling increases, the empirical residual distribution shows excess kurtosis and negative skewness. Occasional market integration will tend to pull gas prices down from the, on average, higher gas prices present under decoupling. We would tend to over-reject normality of residuals in the linear model.

\section{Accounting for Periodic Decoupling}

To account for periodic decoupling of natural gas from oil prices, we formulate a Markov Switching model for natural gas prices. Since its introduction by Hamilton (1989), the Markov Switching, or regime-switching model has become a staple model in the class of non-linear time series models. Applications can be found in the business cycle literature (Hamilton, 1989; Ang and Bekaert, 2002; Bansal et al., 2004), and in interest rate modeling (Garcia and Perron, 1996; Gray, 1999; Bansal and Zhou, 2002). For commodity prices, the model has been applied to model peak-load pricing in electricity prices (Mount et al., 2005; Kanamura and hashi, 2008), and to the long-run relationship between natural gas and oil in the US (Brigida, 2014)

We conjecture that the price of natural gas in the UK moves between oil-driven and gas-specific. As such, there are two dominant pricing states. Let $y_{t}$ be the $(\log )$ natural gas price and $x_{t}$ the $(\log )$ oil price. We assume the oil price is weakly exogenous. When oil influences natural gas prices, the gas price will adjust to the oil price to establish a long-run equilibrium relationship between the prices. If oil is cheap relative to gas, gas prices will tend to decline; if oil is expensive, gas prices will tend to increase. With oil-informed pricing, natural gas price is modelled by the following error-correction process 
$\Delta y_{t}=\mu^{(i)}+\alpha^{(i)}\left(y_{t-1}-\beta x_{t-1}\right)+\sum_{i=1}^{p} \beta_{x, i}^{(i)} \Delta x_{t-i}+\sum_{i=1}^{q} \beta_{y, i}^{(i)} \Delta y_{t-i}+\sigma^{(i)} \varepsilon_{t}, \quad \varepsilon_{t} \sim N(0,1)$

where supscript $i$ refers to integration. The parameter $\alpha^{(i)}$ determines how strongly natural gas prices adjust to deviations from the long-run relationship. If the law of one price holds, $\beta=1$, natural gas and oil prices move proportionally. With proportional price movements, the equilibrium relative value of natural gas to oil prices is $\exp \left(\frac{-\mu^{(i)}}{\alpha^{(i)}}+\frac{\left(\sigma^{(i)}\right)^{2}}{2}\right)$. We also allow short-run influences through the lagged price differences.

With gas-specific pricing, decoupling, the level of the oil price does not influence natural gas prices. Natural gas prices in this state is modelled as

$\Delta y_{t}=\mu^{(d)}+\alpha^{(d)} y_{t-1}+\sum_{i=1}^{p} \beta_{x, i}^{(d)} \Delta x_{t-i}+\sum_{i=1}^{q} \beta_{y, i}^{(d)} \Delta y_{t-i}+\sigma^{(d)} \varepsilon_{t}, \quad \varepsilon_{t} \sim N(0,1)$

where supscript $d$ refers to decoupled prices. Model (1a) and (1b) are equivalent when $\beta=0$ in model (1a). This is the case of no oil price informed natural gas pricing in any period (expect possible short-run influences). In model (1b) we do allow short-run influences from oil, this can be tested empirically using conventional methods. If $\alpha^{(d)} \neq 0$ and $\left|\alpha^{(d)}\right|<1$, natural gas prices are stationary and mean-reverting when decoupled. With stationarity, the natural gas price will revert to $\exp \left(\frac{-\mu^{(d)}}{\alpha^{(d)}}+\frac{\left(\sigma^{(d)}\right)^{2}}{2}\right)$. If $\alpha^{(d)}=1$, the natural gas price contains a unit-root when decoupled, and $\mu^{(d)}$ determines the drift in log-returns.

The active pricing state is determined by a $[2 \times 1]$ state vector $S$, where $S=[1,0]^{\prime}$ if pricing is in state one, and $S=[0,1]^{\prime}$ if in state two. Referring to integration or decoupling as state one or two is arbitrary. The state vector evolves in time according to a two-state Markov process with transition probability matrix $P$. If $S_{t \mid t}$ is the time $t$ state of the market, inferred using all available information 
up to and including time $t$, the projected next period state is $S_{t+1 \mid t}=P S_{t \mid t}$. Let $f_{t+1}$ be the $[2 \times 1]$ vector of likelihoods for each pricing state at time $t+1$. The state vector is updated according to $S_{t+1 \mid t+1}=f_{t+1} \odot S_{t+1 \mid t} / f_{t+1}{ }^{\prime} S_{t+1 \mid t}$, where $\odot$ is element-by-element multiplication. Given a starting state $S_{0 \mid 0}$, the complete likelihood at time $t+1$ with states integrated out is $l_{t+1}=$ $S_{t+1 \mid t}{ }^{\prime} f_{t+1}$. With the states integrated out, the likelihood can be maximized using conventional maximum likelihood methods. Given parameter estimates, we run a backwards recursion at the end to derive states incorporating the full sample information. This produces the smoothed states $S_{t \mid T}$.

\section{Empirical Analysis}

Our measure of the oil price is the crude oil Brent FOB front month price denoted in $\$ / M M b t u$. The natural gas price is the ICE Natural Gas front month price, also denoted in $\$ / M M b t u$. The National Balancing Point (NBP) in the UK is the pricing and delivery point of ICE natural gas contracts. All data are weekly from week 6 in 1997 to week 18 in 2014. The ICE natural gas and Brent oil prices are both integrated of order one. Table 1 shows results from the Augmented Dickey Fuller test for a null of a unit-root and the KPSS test with a null of stationarity. The Johansen (1988) trace test for cointgration show strong evidence for cointegration over the full sample.

Table 1. Stationarity and cointegration test results

\begin{tabular}{|c|c|c|c|c|c|}
\hline \multicolumn{3}{|c|}{ Stationary tests } & \multicolumn{3}{|c|}{ Cointegtration test } \\
\hline & ADF statistic & KPSS statistic & HO: rank <= & Trace statistic & $p$-value \\
\hline ICE natural gas & -1.168 & $6.450 * *$ & 0 & 49.888 & $<0.000$ \\
\hline Brent oil & -2.153 & $5.495 * *$ & 1 & 2.8724 & 0.612 \\
\hline ICE natural gas $1^{\text {st }}$ diff. & $-8.687 * *$ & 0.0491 & & & \\
\hline Brent oil $1^{\text {st }}$ diff. & $-8.407 * *$ & 0.0271 & & & \\
\hline
\end{tabular}

Note: ${ }^{* *}$ rejection at $1 \%$ critical values. Lags for the cointegration test selected using AIC.

In the linear VECM representation of price dynamics, oil is weakly exogenous both in terms of not adjusting to deviations from the long-run equilibrium relationship ( $p$-value 0.4701 ), or to short-run gas price movements ( $p$-value 0.8164$)$. Natural gas adjusts to both cointegration errors ( $p$-value < 
0.0000 ), and short run oil price movements ( $p$-value $<0.0000$ ). The long-run relationship in log prices is $y_{t}=0.196+0.859 x_{t}$, and we reject the law of one price ( $p$-value 0.0139 ). The sample mean relative value of natural gas to oil (on an equivalent energy basis) is 0.629 . This translates to a barrel of oil historically trading at 9.2 times the price of one MMbtu of natural gas.

Table 2 shows estimation results for the regime-shifting model. Standard errors are by re-estimating the model on 1000 price data replicas from the estimated model ${ }^{2}$. If pricing is currently in a state of integration, the probability of remaining in this state the next period is 0.94 , the probability of remaining in a decoupling state is 0.73 . This means that prices favour integrated markets $63.36 \%$ of time from 1997 to 2014. During integration, natural gas prices adjust to deviations from the long-run equilibrium relationship with a coefficient of -0.047 . This is a stronger adjustment than in the linear model (-0.039), consistent with the simulation experiment above. We find strong support for the law of one price holding when markets are integrated, the estimated beta coefficient is 1.001 . The gas price when integrated also adjusts to short-run movements in oil prices.

Table 2. Estimation results with decoupled pricing state

\begin{tabular}{|c|c|c|c|c|c|c|c|}
\hline \multicolumn{5}{|c|}{ Integration Regime (oil pricing) } & \multicolumn{3}{|c|}{ Decoupled Regime (gas-specific) } \\
\hline & Coefficient & S.E. $^{1}$ & t-stat. & & Coefficient & S.E. $^{1}$ & t-stat. \\
\hline$\mu^{(i)}$ & -0.030 & 0.003 & -9.531 & $\mu^{(d)}$ & 0.042 & 0.016 & 2.702 \\
\hline$\alpha^{(i)}$ & -0.047 & 0.005 & -9.735 & $\alpha^{(d)}$ & -0.022 & 0.020 & -1.293 \\
\hline$\beta$ & 1.001 & 0.073 & 13.629 & - & & & \\
\hline$\beta_{x, 1}^{(i)}$ & -0.053 & 0.027 & -2.004 & $\beta_{x, 1}^{(d)}$ & 0.026 & 0.187 & 0.134 \\
\hline$\beta_{y, 1}^{(i)}$ & 0.237 & 0.033 & 7.215 & $\beta_{y, 1}^{(d)}$ & 0.093 & 0.093 & 0.794 \\
\hline $\log \left(\sigma^{(i)}\right)$ & -6.885 & 0.228 & -30.198 & $\log \left(\sigma^{(d)}\right)$ & -4.816 & 0.202 & -24.028 \\
\hline$p_{11}$ & 0.940 & & & $p_{22}$ & 0.732 & & \\
\hline
\end{tabular}

Note: S.E. ${ }^{1}$ is bootstrapped standard errors. The t-statistic calculated using finite sample bootstrapped standard errors.

When the data favours decupling, the adjustment coefficient $\alpha^{(d)}$ to own price levels is not significantly different from zero. Prices in levels contain a unit-root, as is consistent with the unit-root

\footnotetext{
${ }^{2}$ Table 4 in the appendix also shows the asymptotic standard errors.
} 
test in table 1. During decoupling, there is significant positive drift, $\mu^{(d)}>0$. This means that when natural gas price decouples, prices tend to increase, consistent with peak-load pricing as a component in decoupling. There is no adjustment to short-run oil or natural gas price movements when decoupled. We also observe that natural gas prices display substantially more short-run volatility when decoupled.

Having derived the pricing states, we can use these to construct a refined measure of relative values. When evidence favours integration and proportional price movements (probability of being in the integration state $>0.5$ ), the mean value of one barrel of oil is 10.04 times the value of one MMbtu of natural gas. This confirms the industry 10-1 rule-of-thumb for relative values. When evidence favours decoupling, the relationship is $8-1$. With decoupling, the natural gas price tends to be increasing, leading to a lower relative value of oil to natural gas. In this state, however, oil prices do not influence natural gas prices, so the relative value is a statistical construct with no direct economic relevance or usefulness in predicting natural gas price adjustments. As stated above, using the full sample and not accounting for periodic decoupling the relationship is 9.2-1. The full sample estimate includes the decoupling periods, overvaluing natural gas to oil. The important lesson here is that when applying the 10-1 rule-of-thumb, for instance to say something about future natural gas price adjustments, this is only economically meaningful and relevant when applied to periods where oil actually influences natural gas prices. Applying the 10-1 rule unconditionally, one would undervalue natural gas on average. 


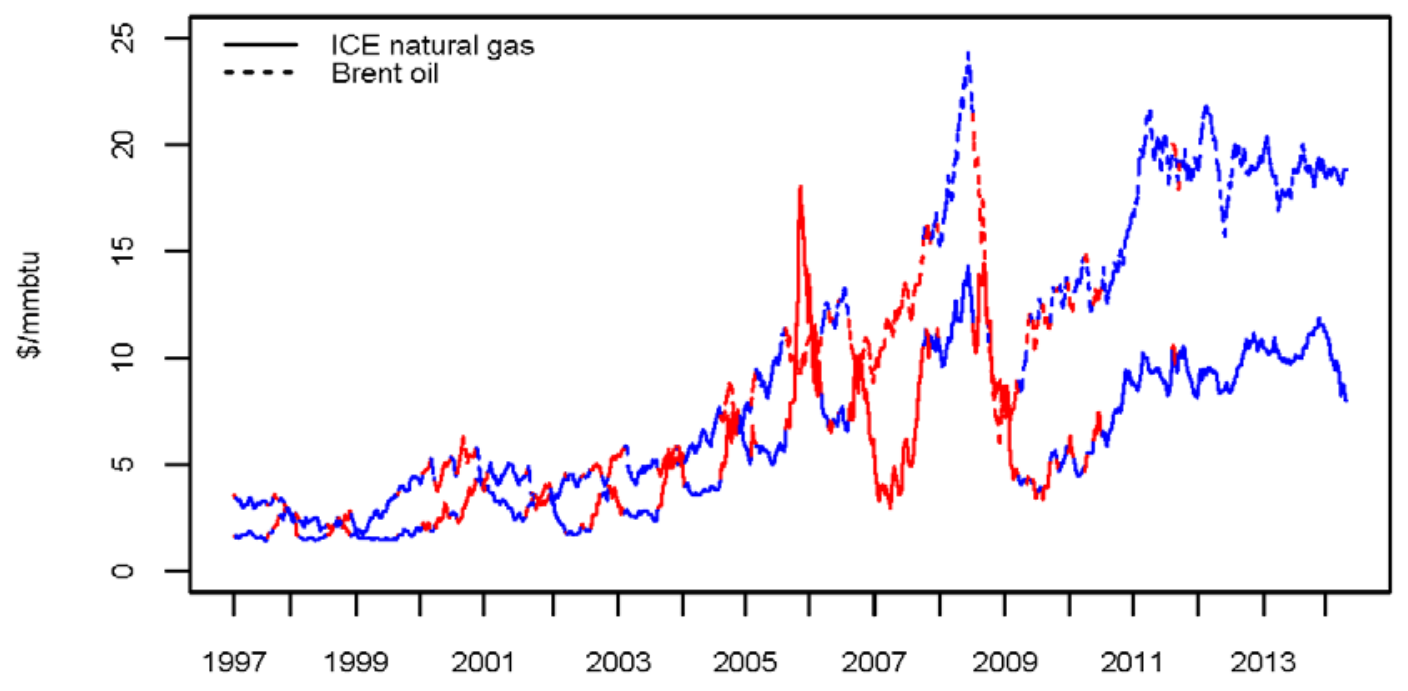

FIGURE 3. The price of natural gas (solid) and oil (dotted) when integrated (blue) and decoupled (red).

Figure 3 shows prices on an equivalent energy basis $(\$ / \mathrm{mmbtu})$. The blue segments are periods when the data indicates integrated markets (probability of integration $>0.5$ ), the red when the data suggest decoupling. From the figure, decoupled pricing is associated with the periodic seasonal fall/winter pricing of gas. This was especially prevalent from around 2001 to 2006, but does appear less relevant in recent years. There is a large divergence in pricing between starting in 2006, when the oil price started increasing substantially. Following the financial crisis and the subsequent stabilization of oil prices, pricing favours integrated oil and natural gas markets in the UK. There is little evidence of divergence or seasonal pricing of natural gas in the latter part of the sample. 


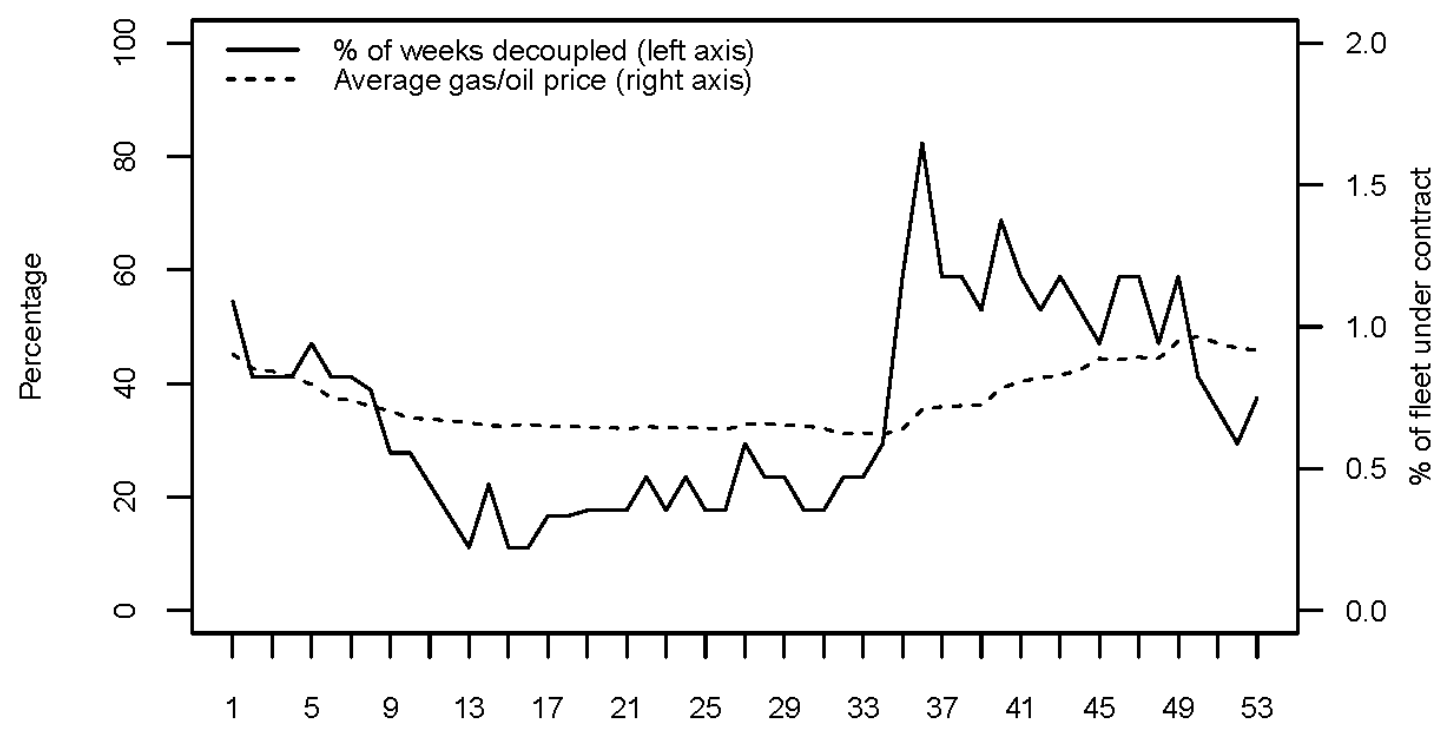

Week

FIGURE 4. Weekly average of probability of decoupled gas-prices (solid) and the average price ratio

In figure 4, we break down the seasonal pattern in pricing states. The figure shows the weekly average probability of being in a decoupled pricing state, along with the weekly average gas/oil price ratio. There is a clear seasonal pattern to when prices tend to decouple. This coincides with the fall/winter pricing of natural gas. Starting in September, the probability of being decoupled increases to around $80 \%$, and remains relatively high throughout winter. This is consistent with seasonal pricing where a larger share of available natural gas is valued according to flow demand for electricity generation or direct heating. The probability of decoupled pricing is low in spring and summer (around April to August), where evidence favours oil driven pricing. Here flow demand for natural gas is lower and gas infrastructure more available.

In the appendix, we investigate the validity of the regime-switching model and its specification. We test the two-state model against the one-state linear model (model (1a) estimated over the full sample) by bootstrapping likelihood ratio statistics. The results here reject the one-state model in 
favour of the two-state model. We also investigate how well the regime-switching model encompasses features of natural-gas prices. The model accounts for skewness and kurtosis in prices, as well as autoregressive heteroskedasticity and serial correlation. We compare these encompassing results to the linear model, and linear model with a $\operatorname{GARCH}(1,1)$ error term, and find that the regimeswitching encompasses features of the data better than these competing models. Finally, we explore the bias in parameter estimates on data simulated from the estimates estimated regime-switching model. Results show that when the data is known to be from regime-switching dynamics, the estimated regime-switching model does produce the correct estimates on average.

\section{Concluding Remarks}

The fact that natural gas demand tend to be seasonal (Asche et al., 2008) together with limited pipeline capacity, imply that seasonal peak load pricing can occur. While electricity markets experience extreme price peaks of short duration, the storability of natural gas suggests less extreme price movements in general and smoother seasonal pricing. Periods of gas-specific pricing leads to periodic decoupling of natural gas from oil prices. A number of studies (Serletis and Herbert, 1999; Asche et al., 2006; Panagiotidis and Rutledge, 2007; Asche, Misund, et al., 2013) suggest that the relationship between the oil and the gas price is stable over time using a linear specification. However, when using conventional (log) linear models, such as error correction models, periodic decoupling can lead to weaker estimates of cointegration relationships, price adjustments and equilibrium relative values.

We propose the use of regime-switching models to account for changes between integrated and decoupled gas pricing. We demonstrate that this approach leads to unbiased estimates of cointegration relationships, adjustments, as well as equilibrium relative values. Estimating the model on UK natural gas and Brent oil prices, we find that markets have been integrated for the majority of the sample (1997-2014). When they are integrated, the law of one price also holds. This is contrary to 
the linear error correction estimator, which rejects the law of one price over the whole sample. Gas prices also adjust more strongly to oil prices, when they are integrated, than what is suggested by the linear estimator. When gas prices decouple they follow a random walk with positive drift. They tend to increase relative to oil prices and become more volatile. This is linked to the winter pricing of gas. The probability of gas-specific pricing increases substantially during the fall and winter. We also find evidence of decoupling during the early ramp up in oil prices starting in 2006 . We do find that market integration has become stronger in recent years (from around 2010/11 to now), coinciding with a period of stable oil and weaker seasonal pricing of gas.

Using the sample mean of relative values, one barrel of oil has on average traded at 9.2 times the price of one MMbtu of natural gas. However, this overstates the economic value of natural gas to oil since relative prices are calculated over periods when no meaningful economic relationship exist between the markets. Using only periods when evidence favours integration and proportional price movements, we find that one barrel of oil is, on average, 10 times the value of one MMbtu of natural gas, confirming the 10-1 industry rule-of-thumb. The lesson here is that when applying the 10-1 ruleof-thumb, for instance to say something about future natural gas price adjustments, this is only economically meaningful and relevant when applied to periods where oil actually influences natural gas prices. Applying the 10-1 rule unconditionally, one would undervalue natural gas on average.

\section{References}

Agerton, M. 2014. "Global LNG Pricing Terms and Revisions: An Empirical Analysis."

Ang, A., and G. Bekaert. 2002. "International Asset Allocation with Regime Shifts." The Review of Financial Studies no. 15 (4):1137-1187.

Asche, F., B. Misund, and M. Sikveland. 2013. "The relationship between spot and contract gas prices in Europe." Energy Economics no. 38:212-217.

Asche, F., O.B. Nilsen, and R. Tveterås. 2008. "Natural gas demand in the European household sector." The Energy Journal:27-46.

Asche, F., A. Oglend, and P. Osmundsen. 2013. "UK Natural Gas: Gas-Specific or Oil Driven Pricing?".

Asche, F., P. Osmundsen, and M. Sandsmark. 2006. "The UK market for natural gas, oil and electricity: are the prices decoupled?" The Energy Journal:27-40. 
Asche, F., P. Osmundsen, and R. Tveterås. 2002. "European market integration for gas? Volume flexibility and political risk." Energy Economics no. 24 (3):249-265.

Bansal, R., G. Tauchen, and H. Zhou. 2004. "Regime shifts, risk premiums in the term structure, and the business cycle." Journal of Business \& Economic Statistics no. 22 (4):396-409.

Bansal, R., and H. Zhou. 2002. "Term Structure of Interest Rates with Regime Shifts." The Journal of Finance no. 57 (5):1997-2043.

Bencivenga, C., G. Sargenti, and R. D'Ecclesia. 2011. "Integration of energy commodity markets in Europe and the USA." Journal of Risk Management in Financial Institutions no. 4 (3):301-313.

Brigida, M. 2014. "The switching relationship between natural gas and crude oil prices." Energy Economics no. 43:48-55.

Brown, S.P.A., and M.K. Yucel. 2008. "What drives natural gas prices?" Energy Journal no. 29 (2):45.

Castle, J.L., and D.F. Hendry. 2010. "A low-dimension portmanteau test for non-linearity." Journal of Econometrics no. 158 (2):231-245.

Deaton, A., and G. Laroque. 1992. "On the Behaviour of Commodity Prices." The Review of Economic Studies no. 59 (1):1-23.

Erdos, P. 2012. "Have oil and gas prices got separated?" Energy Policy.

Garcia, R., and P. Perron. 1996. "An Analysis of the Real Interest Rate Under Regime Shifts." The Review of Economic and Statistics no. 78(1):111-125.

Geman, H.e.I., and A. Roncoroni. 2006. "Understanding the Fine Structure of Electricity Prices*." The Journal of Business no. 79 (3):1225-1261.

Gray, S.F. 1999. "Modeling the conditional distribution of interest rates as a regimeswitching process." Journal of Financial Economics no. 42(1):27-62.

Hamilton, J.D. 1989. "A New Approach to the Economic Analysis of Nonstationary Time Series and the Business Cycle." Econometrica no. 57(2):357-384.

Hamilton, J.D., and R. Susmel. 1996. "Autoregressive Conditional Heteroskedasticity and Changes in Regime." Journal of Econometrics no. 64:307-333.

Johansen, S.o.r. 1988. "Statistical analysis of cointegration vectors." Journal of economic dynamics and control no. 12 (2):231-254.

Kanamura, T., and K. hashi. 2008. "On transition probabilities of regime switching in electricity prices." Energy Economics no. 30 (3):1158-1172.

Kerr, R.A. 2010. "Natural gas from shale bursts onto the scene." Science no. 328 (5986):16241626.

Lucia, J.J., and E.S. Schwartz. 2002. "Electricity prices and power derivatives: Evidence from the nordic power exchange." Review of Derivatives Research no. 5 (1):5-50.

Mount, T.D., Y. Ning, and X. Cai. 2005. "Predicting Price Spikes in Electricity Markets using a Regime-Switching Model with Time Varying Parameters." Energy Economics no. 28(1):62-80.

Oglend, A., M. Lindback, and P. Osmundsen. 2016. "Shale Gas Boom Affecting the Relationship Between LPG and Oil Prices." Energy Journal no. 37 (1):211-232.

Panagiotidis, T., and E. Rutledge. 2007. "Oil and gas markets in the UK: Evidence from a cointegrating approach." Energy Economics no. 29 (2):329-347.

Parsons, D.J., and J.E. Ramberg. 2012. "The Weak Tie Between Natural Gas and Oil Prices." The Energy Journal no. 33 (2). 
Pirrong, C. 2012. Commodity Price Dynamics: A Structural Approach: Cambridge University Press.

Serletis, A., and J. Herbert. 1999. "The message in North American energy prices." Energy Economics no. 21 (5):471-483.

Siliverstovs, B., G. L'Hégaret, A. Neumann, and C. Von Hirschhausen. 2005. "International market integration for natural gas? A cointegration analysis of prices in Europe, North America and Japan." Energy Economics no. 27 (4):603-615.

Villar, J.A., and F.L. Joutz. 2006. "The relationship between crude oil and natural gas prices." EIA manuscript, October.

Wright, B.D., and J.C. Williams. 1991. Storage and Commodity Markets. Edited by Cambridge: Cambridge University Press.

\section{Appendix. Model Validation}

When evaluating regime-switching models, an immediate problem is that the linear (one-state) model is not nested within the two-state model. This is because transition probabilities are not identified in the one-state model. We cannot use conventional likelihood ratio statistics to evaluate the regime-switching model against its linear model counterpart. Estimating the linear error correction model (1a), and testing for non-linearity using powers of orthogonalized regressors (Castle and Hendry, 2010) does suggest non-linearity is present in the linear model (p-value 0.0204). To circumvent the nuisance parameter problem we derive the finite sample likelihood-ratio distribution under the null of a linear model. We estimate both the linear error correction model (1a) and the two-state regime-switching model ( $1 \mathrm{a}$ and $1 \mathrm{~b})$ on data bootstrapped from the estimated linear error correction model (just model (1a) over the full sample). By construction, the regime-switching model is estimated on data without any regime-switching dynamics. This is a test for the linear one-state model 1a against the alternative two-state regime-switching model (model $1 \mathrm{a}$ and $1 \mathrm{~b}$ ). The $95 \% / 99 \%$ critical values of the bootstrapped likelihood ratio are $40.53 / 82.74$. The likelihood ratio estimated on the actual data is 278 , so we reject the one-state model in favour of the two-state model. 
Table 3. Properties of model residuals

\begin{tabular}{lcccccccc}
\hline & \multicolumn{2}{c}{ Regime shift $^{1}$} & \multicolumn{2}{c}{ Regime shift } & \multicolumn{2}{c}{ Linear } & \multicolumn{2}{c}{ Linear GARCH } \\
& Statistic & p-value & Statistic & p-value & Statistic & p-value & Statistic & p-value \\
\cline { 2 - 10 } & 0.0313 & - & -0.0087 & - & 0.6699 & - & 0.7685 & - \\
Skewness & 0.0714 & - & -0.2013 & - & 3.8807 & - & 2.7143 & - \\
Excess Kurtosis & 0.3387 & 0.8442 & 1.5348 & 0.4642 & 633.4700 & 0.0000 & 365.6900 & 0.0000 \\
Normality & 25.6020 & 0.3737 & 27.3680 & 0.2876 & 55.7570 & 0.0002 & 49.5840 & 0.0016 \\
Portmanteau (24) & 20.8674 & 0.4050 & 22.3257 & 0.3231 & 45.2257 & 0.0010 & 41.3753 & 0.0033 \\
Box Pierce Q(20) & 0.2735 & 0.7608 & 2.1665 & 0.1152 & 10.8590 & 0.0000 & 2.0954 & 0.1236 \\
ARCH 1-2 test: & 1313.2 & - & 1313.2 & - & 1174.19 & - & 1280.85 & - \\
Log-likelihood & 11 & - & 11 & - & 5 & - & 8 & - \\
\# parameters & & & & & & & &
\end{tabular}

Note: Normality is the Jarque-Bera $\chi^{2}(2)$ test for normality of residuals. Portmanteau (24) and Box Pierce $Q(20)$ are tests for autocorrelation in residuals ( 24 and 20 lags each), and ARCH 1-2 is the F-test for significant ARCH effects up to 2 lags. Supsrcipt ${ }^{1}$ and ${ }^{2}$ on the regime shift model refer to residuals calculated using the smoothed states (using the full sample information), and residuals calculated using states inferred up to time $t$ for state at time $t$ respectively.

An alternative method to investigate the validity of the regime-switching model is to look at how well the model encompasses different features of the data. To do this we extract the empirical residuals from the estimated model. We need to integrate out the pricing state to arrive at the residuals since each state has a separate residual series. We produce two sets of empirical residuals, one where states are integrated out using the full sample inference on states, the smoothed states, and one using the time $t$ state inferred using information up to time $t$, the filtered states. These are distinguished by supscript 1 and 2 in the table. We also evaluate the residuals from the linear error correction model, and the linear error correction model with a GARCH $(1,1)$ error-term. Table 3 shows the encompassing results. The regime-switching model accounts for both skewness and kurtosis and residuals satisfy the Jarque-Bera test for normality. This is contrary to both the linear and linear GARCH model, which show evidence of positive skewness and excess kurtosis. The regime-switching model residuals show no evidence of autocorrelation or ARCH effects. Again, the linear model has unaccounted residual autocorrelation and heteroskedasticity. Appending the GARCH error-term eliminates most of the ARCH effects, but not the residual autocorrelation. Although the regimeswitching model has desirable descriptive properties, it is more heavily parametrized. Clearly, variations in volatility is a major component in the regime switching, as is evidenced by the substantial difference in volatility between the regimes. Appending a GARCH term improves the fit 
substantially over the linear model, but it is still worse than the regime-switching model in terms of likelihood values. The likelihood ratio between the regime-switching model and linear GARCH model is 64.7, however again the models are non-nested.

Table 4. Estimation bias and standard errors (bootstrapping)

\begin{tabular}{cccccccc}
\multicolumn{4}{c}{ Integration Regime (oil pricing) } & \multicolumn{3}{c}{ Decoupled Regime (gas-specific) } \\
\hline$\mu^{(i)}$ & Bias & S.E. ${ }^{1}$ & S.E. ${ }^{2}$ & & Bias & S.E. $^{1}$ & S.E. $^{2}$ \\
$\alpha^{(i)}$ & -0.0004 & 0.006 & 0.003 & $\mu^{(d)}$ & 0.0016 & 0.014 & 0.016 \\
$\beta$ & -0.0010 & 0.010 & 0.005 & $\alpha^{(d)}$ & -0.0035 & 0.008 & 0.020 \\
$\beta_{x, 1}^{(i)}$ & -0.0044 & 0.049 & 0.073 & - & & & \\
$\beta_{y, 1}^{(i)}$ & -0.0016 & 0.045 & 0.027 & $\beta_{x, 1}^{(d)}$ & -0.0006 & 0.095 & 0.187 \\
$\log \left(\sigma^{(i)}\right)$ & -0.0016 & 0.051 & 0.033 & $\beta_{y, 1}^{(d)}$ & -0.0185 & 0.051 & 0.093 \\
& & & & & & & \\
\end{tabular}

Note: S.E. ${ }^{1}$ is asymptotic standard errors, S.E. ${ }^{2}$ is bootstrapped standard errors.

As a final test, we investigate how well the regime-switching estimator performs on data generated by true regime-switching dynamics. This is an investigation of estimator bias. We want the estimator to produce the correct estimates when data is generated by the model. We derive 1000 price replicas from the estimated regime-switching model, and proceed to re-estimate the regime-switching model on these data. The mean estimator bias and their coefficient standard errors are show in table 4 . The table also shows asymptotic standard errors (supscript 1) for comparison. The estimator does appear to perform well with only small biases in most parameters. This includes inferring the correct cointegration relationship (the $\beta$ coefficient), and the correct gas price adjustment to cointegration errors $\left(\alpha^{(i)}\right)$. For comparison, the mean linear estimator of $\beta$, estimated on the same data is 0.86 , substantially below the true value of 1.001 . It is interesting to note that the mean linear estimate of 0.86 on the bootstrapped data is the same as that produced by the linear estimator when applied to the actual data. This suggests that the regime-switching model does account for relevant dynamics in gas prices. 